\title{
Blockchain and Smart Contract's Contributions to Zakat Management System
}

\author{
Dhiaeddine Rejeb \\ Sakarya University \\ Paper to be presented at the $4^{\text {th }}$ International Conference of Zakat (ICONZ) \\ 7-8 October 2020, Surabaya, Indonesia
}

\begin{abstract}
Blockchain is an open distributed database that carries out transactions on an open decentralized ledger. It is a technology that will probably be the source of a huge digital change especially in the financial sector. The application of this technology has started to take its first steps recently and its importance is undeniable in an emerging and expanding field such as Islamic finance. In this context, the purpose of this article is to study the integration of the blockchain and one of its important components, namely the smart contract in the management of the compulsory Islamic charity the zakat. To do this, we have developed a funding model linking all the stakeholders in question and the diversities of blockchain technology. We were thus able to conclude huge benefits and technical contributions in this context which encourages Islamic financial institutions to develop more models likely to support this technology without ignoring the compliance with the Islamic jurisprudence rules.
\end{abstract}

Keywords: Blockchain, smart contract, Islamic finance, zakat

\section{INTRODUCTION}

As a mandatory charity which is taken from the wealthy class and distributed among poors, Zakat comes as the third pillar in the Islamic religion and is considered one of the most important rituals that a Muslim should strive to perform according to its requirements and rules and in its specified deadlines. The term "Zakat" originates from three different senses from sharia perspective: sanctifying (at-thaharatu), developing (annamaa), and blessing (al-barakatu). It strongly contributes to strengthening social well-being, eradicating poverty and empowering people (Friantoro \& Zaki, 2018). It is designed to be given to specific categories of society (masarif al-zakat) mentioned in the Quran. In the zakat process, the giver of zakat is called muzakee while the receiver is called mustahiq.
With the increasing evolution of Islamic finance over the past decades, zakat has taken its part in the practical side by being present through a number of zakat management institutions in both Islamic and non-Islamic countries. Very similar to normal charities from the operational and systematic side, in addition to its spiritual benefits, these institutions strongly contribute to increase social wellbeing and alleviate poverty. In fact they aim to develop a system for collecting monetary and non-monetary alms from individuals who have fulfilled the conditions of the obligation to pay zakat as well as distributing these collected donations to indigent individuals and those who belong to the zakat categories (Masarif al-zakat) of people needing social support within the limits of Islamic jurisprudence.

Collecting zakat is a fairly delicate operation that requires institutional organization and powerful marketing 
work. One of the biggest challenges for zakat institutions as well as charities in the general context is their inability to prove their transparency and reliability and thus donor's trust and interest. As for zakat institutions, the problem is more prominent due to its importance within the framework of Sharia and the Muslim's keenness to perform it correctly and in its best way, which puts him in an environment of doubt. Moreover, the problem is further heightened in cases of natural disasters and socio-human crises where there is a need for emergency intervention and transfer of these handouts as quickly as possible just like the living conditions resulting today from the spread of the COVID 19 pandemic.

It is in this conceptual field that a new technology called blockchain has recently emerged. The idea is to create a transparent and reliable environment for exchanging data and carrying out transactions through a decentralized and immutable network system. As a result, all the transactions carried out will be visible and authenticated by all the nodes in the network which makes it possible to track funds while being transferred in full transparency and makes any fraud operation impossible and protects against cyber-attacks. Blockchain should therefore be a perfect solution for Zakat institutes to overcome its drawbacks while allowing people to know exactly where and for which purpose their money was used (Peredaryenko, 2019). It can also contribute to higher transparency in charitable giving and increase clarity of the links between charitable giving and project results (Cole, Stevenson, \& Aitken, 2020).

A body of blockchain-based projects and models for managing donations for charities has been developed within this framework, one of the most important and recent is Hyperchain who developed a platform model to track donations collected to support governments and health care organizations in donation process to infected victims in China (Nguyen, Ding, Pathirana, \& Seneviratne, 2020). Actually, this concrete example reflects the aspiration of aid agencies to work with a more direct aid transfer model and blockchain plays an important contributory role in this context by making the donation sector digitized and more adapted to the future (De Vrij, 2018).

Unlike charities, the use of digital wallets in zakat distribution and collection operations is not yet a common activity, since it is mandatory to conduct studies on the adoption of these technologies and its compliance to sharia (Salleh, Abdul Rasid, \& Basiruddin, 2019). All the more so, the complexity and still relatively ambiguous aspect of blockchain technology despite its enormous potential reinforces this assertion. Within this framework, a blockchain-based zakat management model is developed in this paper with the aim of opening the way for zakat institutions to be more reliable and transparent and to operate in a digital and innovative ecosystem within blockchain components. Our model also includes Smart contracts - a tiny computer program stored in a blockchain that takes the form of digital self-executing contracts without human intervention and which are created by using a distributed ledger to store contracts-.We will then also discuss the technical and operational contributions of our model in this whole framework.

The remainder of this paper is structured as follows: Section 2 includes the literature review. We discuss in section 3 the technical comprehensive framework of our model and in section 4 the proposed architecture and its benefits. Finally, section 5 serves as the conclusion. 


\section{LITERATURE REVIEW}

\section{Blockchain}

Blockchain is an open distributed database that carries out transactions on an open decentralized ledger (Nor, Rahman, Rahman, \& Abdullah, 2017). More specifically it's about a data chain of transactions between users stored in blocks where each block records a specific amount of data encrypted thanks to cryptographic hashing. If a user wishes to carry out a transaction, he must communicate it to all other network users so that they can verify the authenticity of the operation. Each user will have a copy of the data ledger, thus all transactions are visible and available to all of them which makes impossible any false transaction, fraud act, or hacking operation. In addition to transparency, reliability and the possibility of precise and detailed fund tracking, the decentralized structure of a blockchain network reduces transaction costs by eliminating any intermediary.

Transaction promotion process in blockchain begins first by creating a digital security code by making encryption. The second step is where users attempt to authenticate the transaction while preserving private information. Finally, the transaction is thus recorded in an immutable way and will be automatically distributed to all users (Changa, Baudierb, Zhangc, Xua, Zhanga, \& Aramid, 2020). The process explained above is shown in the following figure.
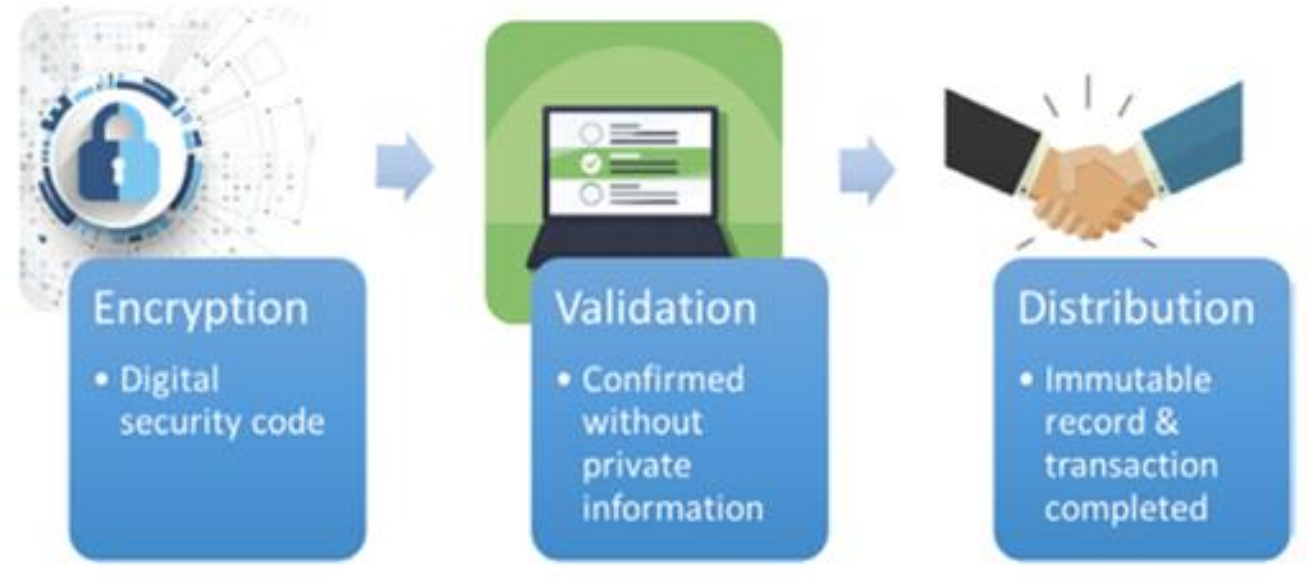

Figure 1. How Blockchain promotes transactions

Source: (Changa, Baudierb, Zhangc, Xua, Zhanga, \& Aramid, 2020)

\section{Smart Contracts}

Perceived as an innovation that will make a technological and organizational disruption over a wide area, smart contracts are expected to be the future of a whole automated, immutable and transparent institutional ecosystem. That said, traditional contracts, taking the form of physical paper, are exposed to nontransparency, fraud risks and slowness. Although this could be resolved relatively by delegating a financial intermediary, high costs will be recommended above (Cant, et al., 2016). But thanks to smart contracts, transactions will be independent, transparent, without financial intermediary and therefore at low cost and reliable since they are the result of a programming process.

Smart contracts were developed by Szabo (1993), at that period, it could not be spread on a large scale given the lack of a technology sufficiently able to support such fields of programming, until the 
appearance of blockchain technology. Thanks to blockchain, smart contract technology strongly stood out, and more specifically, it was thanks to Ethereum decentralized exchange protocol which allows users to create smart contracts for exchanges while using a cryptographic currency called Ether as an account unit. Thus, most of smart contracts today are being applied on blockchain platforms (Feng, Yu, Chai, \& Liu, 2019). There are different types of blockchain, and smart contracts do not always operate in the same blockchain type. For example, while Hyperledger Fabric applies the alliance chain, Ethereum smart contract model mainly uses the public chain platforms (Feng, Yu, Chai, \& Liu, 2019). Thanks to blockchain and distributed ledger technology a smart contract will be impossible to hack and therefore protected from any kind of falsification. Although smart contracts are adequate to be used in a multiple of activity sectors, they remain the most sought in the financial sector where transactions suffer in general from heaviness, slowness, lack of transparency and high costs.

\section{Zakat}

Zakat, as a tremendously effective tool for poverty minimization and social problems resolution, just like digital wallets can be used and optimised within the potential use of blockchain technology (Salleh, Abdul Rasid, \& Basiruddin, 2019). A project called "ZakatTech" in collaboration between the International Shariah Research Academy for Islamic Finance (ISRA) and SysCode was announced in 2019. This project will allow funds to be tracked throughout the Zakat management process from collection to distribution (IFNFintech, 2019).

In general, this applies in the same way to the charities. Much like zakat, blockchain is well suited to the charitable giving, foreign aid and development sectors that require the common use of direct payments and cash transfers (Vrba, 2018). This is why many academic works have developed models integrating blockchain into the modus operandi of charities and donation companies. (Farooq, Khan, \& Abid, 2020) developed a management platform for charity collection and distribution by using a blockchain network as well as its components such as Intial coin offering (ICO), crypto wallets, IPFS protocol and smart contracts. (Hu \& $\mathrm{Li}, 2020)$ developed a token-based blockchain charity system by also presenting the design model, architecture and operational process of the platform. (An \& Seo, 2018) developed a blockchain-based donation system in effort to address the security gap in the current donation system. The model also includes a fundraising society and describes a structured process for using cryptocurrency and turning it into real currency. (Lee, Seo, Kim, \& Jeong, 2018) created a blockchain donation structure designed to strengthen transaction security by keeping stakeholders' personal information private. For the purpose they used the P2P mixing method in order to set up a privacy protection system. All these contributions, based on various components and techniques of blockchain technology, allow the development of dynamic, digital, reliable and transparent donation systems capable of winning donor's confidence and trust.

\section{TECHNICAL COMPREHENSIVE FRAMEWORK}

Integrating blockchain into Zakat management requires setting up a process that improves the efficiency of the operational side and takes into account Sharia-compliance rules.

The system presented in Figure 2 reflects the integration of blockchain technology within the zakat management institution which directly links the muzakees and mustahiqs on a single 
decentralized network. The connection to the network is achieved through a digital wallet and more precisely through decentralized applications (Dapps), every mustahiq who meets the conditions to be part of zakatable categories will have a blockchain account on the network. It is now imperative to explain the key technical points of the model in order to set up the bases of the proposed architecture.

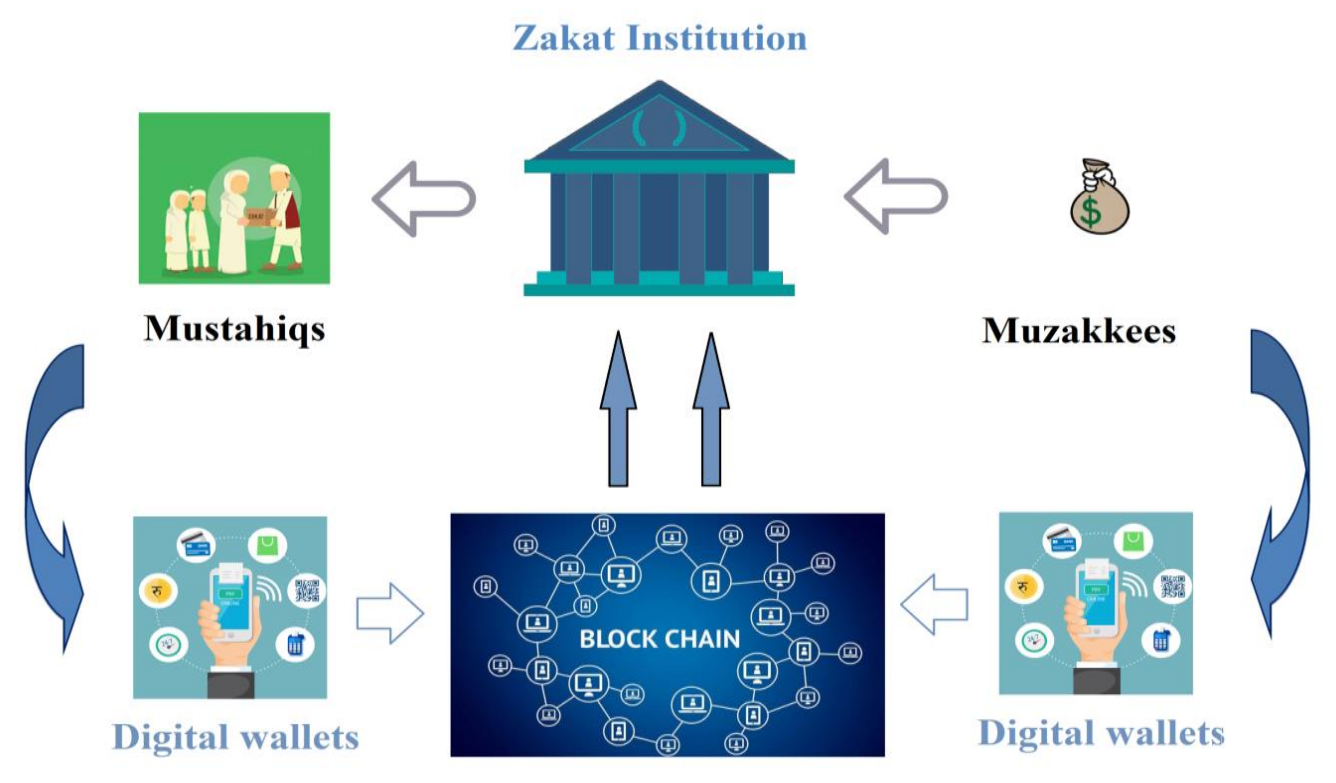

Figure 2. Proposed Framework

\section{Smart Contract Implementation}

Smart contracts will be used in each of Zakat's collection and distribution processes. Furthermore, first we have chosen to adopt a specific smart contract relationship between the muzakkees and zakat institution. For zakat collection, we will implement a smart contract which will be self-executed if the conditions of obligation to pay zakat are satisfied (A minimum of nisâb, which is the recommended minimum threshold of amount in a specific category of zakat, must have been accumulated and remained in possession throughout a lunar year (hawl) ). Once the code in question is filled in, the smart contract will perform a corresponding action which is used here to automatically transfer the recommended zakat amount to the institution in the form of cryptocurrency. Additional costs outside the framework of zakat will also be levied so that they can be used as the operating funds of the Zakat institution. These fees are those of agency contract framework (Wakala).

\section{Cryptocurrency}

The issue of the legality of cryptocurrencies within the framework of sharia is still at the heart of the debate. The complexity of this technology and methods available to acquire this kind of currency makes the question of deciding on its legitimacy more intricate. It is for this reason that we will adopt a neutral position with regards to crypto currencies in the proposed architecture and we will therefore consider it part of the zakatables categories.

Technically speaking, we will not use cryptocurrency more than a medium of exchange throughout the process and for this we will adopt a fixed parity exchange system of 1 local currency for 1 
cryptocurrency unit in order to avoid values fluctuations (An \& Seo, 2018).

\section{Stablecoin: Tether}

We use for this pupose stablecoins which are types of cryptocurrencies designed to provide security relating to other major currencies that reputable central banks struggle to preserve purchasing power over time in the crypto-asset markets (Bullmann, Klemm, \& Pinna, 2019).

This type of cryptocurrency is thus characterized by very low volatility (commonly close to zero). We use "Tether" which is the most famous and commonly used crypto currency for this kind of operations. The big specificity of Tether is that it belongs to the category of stablecoin which is stabilized and fixed by fiat currencies. Tether holds a parity of one Tether unit (1USDT) for 1 dollar.

\section{Connecting Mustahiqs to the Network}

Every mustahiq identified on the zakat institution database will automatically have a blockchain account on the network. $\mathrm{He}$ receives these zakat funds in cryptocurrency form and then transfers them in fiat money on the exchange platform.

\section{PROPOSED ARCHITECTURE}

\section{Process}

The muzakees will apply on the blockchain network of the zakat institution where they will automatically have a permanent account. Their zakatable funds will thus be represented in the form of the Tether crypto-currency. On the other side, each mustahiq on the zakat institution database which has fulfilled the conditions allowing him to be part of those who should be given zakat will also have a blockchain account. Once completed, a smart contract will be signed between the institution and the muzakee where it will be automatically executed i.e zakat funds will be levied in crypto-currency form, if the nisâb is reached and remained one lunar year in possession. Zakat institution will receive operating fund as additional fees. Once the funds are acquired, they will be exchanged for fiat money on the exchange platform for " 1 Tether $=1$ Dollar" parity and transferred to the mustahiq.

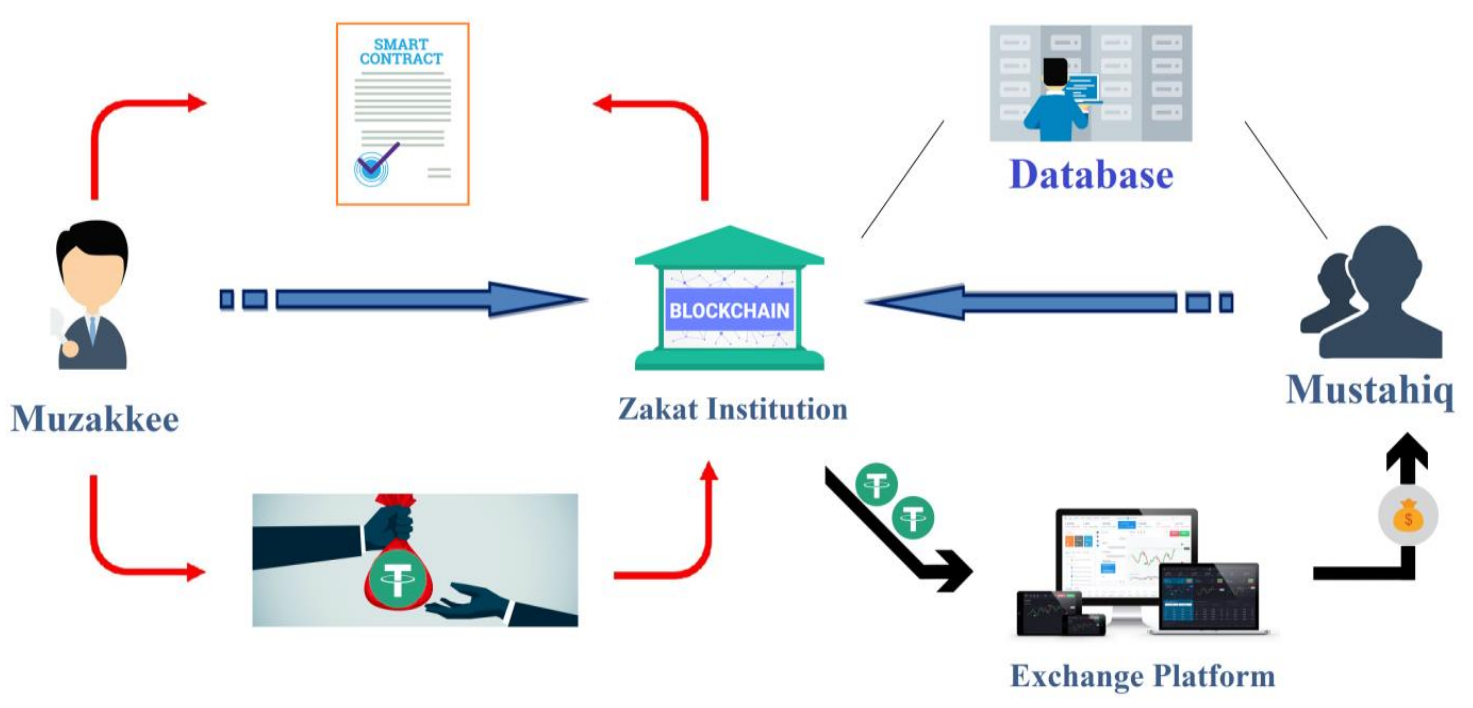

Figure 3. Proposed Architecture 


\section{Benefits}

a. Identifying muzakees

Among the major causes of the rampant poverty perceived in Islamic economies, the zakat non-payment. This comes down to the inability to identify those who have fulfilled the conditions of having to pay zakat. Through the transparency and reliability provided by blockchain technology it would be possible to identify the funds held by the muzakees and thus their accountability or not to pay the zakat while supervising the calculation and funds transfer by a smart contract.

\section{b. Ensure a trust environment}

Earning the donor trust is the key point for charities. However, this factor is more and more decreasing which has caused downward trends in individual donations in recent years. The Charities Aid Foundation affirmed this decline according to its report in 2017 and 2018. Organizations are in many cases accused of illegal exploitation of donations (Farooq, Khan, \& Abid, 2020).

What the Blockchain offers as a solution in this regard is that it limits illegal access to the network or modification of data. As a result, once the data is saved in the blockchain, it can almost never be erased or accessed except by the trusted entity (Farooq, Khan, \& Abid, 2020). Smart contracts applied on blockchain platforms will allow muzakkees to know where their funds have been transferred and for which purposes. Through blockchain technology, collected funds will be accurately tracked to know where and for which purposes they have been used. Thereby, the process will be trackable, auditable, and immutable which are main qualities to ensure a successful zakat raise system (Elasrag, 2019).

\section{c. Time efficiency}

In cases requiring emergency interventions such as natural disasters, wars, epidemics as well as the emerging virus COVID 19 it is extremely important that the donations reach the poor person on time (Farooq, Khan, \& Abid, 2020). Calamities faced nowadays by Islamic countries create an urgent need for Zakat delivery. As a decentralized system with no intermediary, blockchain ensures the satisfaction of this need by consuming little time for the funds to be transferred in emergencies with a quick feedback on the way in which the funds are spent between the muzakee, mustahiq, and the zakat management institution.

\section{d. More efficient muzakee-mustahiq connection}

Contingencies were explored with regard to smart contracts in their ability to link the funder with the financing needs with the entire cash flow matching process carried out via an algorithm (Kasujja, 2018). This paves the way towards a decentralized zakat management system, where muzakkee can easily and efficiently spot mustahiqs by simply connecting via Dapp to the institution's blockchain network and mustahiq also can easily earn zakat funds. Audit reports of every charity activity are also given (Jayasinghe, Cobourne, Markantonakis, Akram, \& Mayes, 2017). This architecture greatly facilitates a future digital link which goes against the traditional problems of centralized systems and will also have its positive impacts by reviving and developing an efficient zakat ecosystem.

\section{e. Accounting processes facilitation}

Among the major problems perceived for the muzakkees refraining from taking proper care of their duty in zakat, their possession of large wealth on which zakat is due, and therefore the need to struggle to calculate the amount of zakat that need to be paid. Since blockchain allows open access to the data of each node and the 
smart contract included in the model ensures an automatic calculation of the nisab, accounting will be automated and therefore this task will no longer be an obstacle. This also applies to the institution of zakat which requires even more complex accounting work. All the inflows and outflows of zakat funds, the calculation data relating to each muzakkee and each mustahiq as well as those relating to cyptocurrency.

\section{f. Remittance efficiency}

In general, the use of smart contracts in the funds transfer system contributes to the facilitation of payment processing and funds transfer to clients and other stakeholders. Some banks have been eager to speed up their remittance systems while preserving accuracy and transparency since smart contract codes are immutable and distributed (Lambert, 2019). Zakat funds transfer in our proposed model is perceived as a complicated operation, that's why being assisted by a smart contract allows it to be fast, accurate and transparent.

\section{g. Avoiding lack of skills problems}

Zakat management is a complex operation which requires institutional know-how and both managerial and academic skills in sharia field. Through the automation of the whole system through blockchain and smart contracts, it will be possible to avoid a large part of these skills problems as well as to avoid the possible errors that can occur. Once the system is installed, all the steps will be automated and enormous material and time consuming costs will be saved (Salleh, Abdul Rasid, \& Basiruddin, 2019).

\section{CONCLUSION}

We have tried in this research paper to highlight the importance of blockchain and smart contracts use in the management of zakat through the development of a model that combines the institution of zakat management with the components of blockchain technology and smart contract. We have seen positive points and benefits, both from a technical point of view and from the Shariah perspective, which strongly encourage the potential application of blockchain in the management of zakat. However, Islamic scholars would need to make clear and neat final decisions regarding the shariahcompliance of some technical aspects such as smart contracts and cryptocurrencies so that future models can be developed for either zakat or for any other branch of Islamic finance.

\section{REFERENCES}

An, K.-h., \& Seo, H. (2018). Donate system development using Blockchain technology. Journal of the Korea Institute of Information and Communication Engineering , 812-817. https://doi.org/10.6109/jkiice.2018.2 2.4.812.

Bullmann, D., Klemm, J., \& Pinna, A. (2019, August). In search for stability in crypto-assets: are stablecoins the solution? European Central Bank. https://www.ecb.europa.eu/pub/pdf/s cpops/ecb.op230 d57946be3b.en.pd f.

Cant, B., Khadikar, A., Ruiter, A., Bronebakk, J. B., Coumaros, J., Buvat, J., et al. (2016). Smart Contracts in Financial Services : Getting from Hype to Reality. Capgemini Consulting. https://www.capgemini.com/consulti ng-de/wpcontent/uploads/sites/32/2017/08/sm art_contracts_paper_long_0.pdf. 
Changa, V., Baudierb, P., Zhangc, H., Xua, Q., Zhanga, J., \& Aramid, M. (2020). How Blockchain can impact financial services - The overview, challenges and recommendations from expert interviewees. Technological Forecasting \& Social Change , 2. https://doi.org/10.1016/j.techfore.20 20.120166.

Cole, R., Stevenson, M., \& Aitken, J. (2020). Blockchain technology: implications for operations and supply chain management. Supply Chain Management , 24 (4), 469483. https://doi.org/10.1108/SCM09-2018-0309.

De Vrij, A. (2018). Blockchain in Humanitarian Aid: A Way out of Poverty and Famine? (Master's thesis, Leiden University, Leiden, Netherlands) Retrieved from : https://openaccess.leidenuniv.nl/han dle/1887/67036.

Elasrag, H. (2019). Blockchain and Its Applications on Islamic Finance. https://books.google.tn/books?hl=fr \&lr $=\& \mathrm{id}=\mathrm{XO7JDwAAQBAJ} \& o i=\mathrm{fn}$ $\mathrm{d} \& \mathrm{pg}=\mathrm{PP} 5 \& \mathrm{dq}=$ Blockchain + and $+\mathrm{Its}$ +Applications+on+Islamic+Finance. \&ots=mZ04DY71Yy\&sig=rtP5PiMv JLva4Hx2MwGh436xpc4\&redir_esc $=\mathrm{y} \# \mathrm{v}=$ onepage $\& \mathrm{q}=\mathrm{Block}$ chain $\% 20 \mathrm{a}$ nd $\% 20$ Its $\% 20$ Applications $\% 20$ on $\% 2$ 0Islamic\%20Fina.

Farooq, M. S., Khan, M., \& Abid, A. (2020). A framework to make charity collection transparent and auditable using blockchain technology. Computers \& Electrical Engineering https://doi.org/10.1016/j.compelecen g.2020.106588.

Feng, T., Yu, X., Chai, Y., \& Liu, Y. (2019). Smart contract model for complex reality transaction. International Journal of Crowd Science

184-186.
https://doi.org/10.1108/IJCS-03-

2019-0010.

Friantoro, D., \& Zaki, K. (2018). Do We Need Financial Technology for Collecting Zakat? INTERNATIONAL CONFERENCE OF ZAKAT, (pp. 227-238). Yogyakarta, Indonesia. https://doi.org/https://doi.org/10.377 06/iconz.2018.133.

Hu, B., \& Li, H. (2020). Research on Charity System Based on Blockchain. IOP Conference Series: Materials Science and Engineering. 10.1088/1757-899X/768/7/072020.

IFNFintech. (2019). ISRA on the hunt for ideal candidates to pilot ZakatTech platform. Retrieved from : https://ifnfintech.com/isra-on-thehunt-for-ideal-candidates-to-pilotzakattech-platform/.

Jayasinghe, D., Cobourne, S., Markantonakis, K., Akram, R. N., \& Mayes, K. (2017). Philanthropy on the Blockchain. Information Security Theory and Practice 11th IFIP WG 11.2 International Conference (pp. 25-38). Heraklion, Crete, Greece: Springer International Publishing. https://link.springer.com/chapter/10. 1007/978-3-319-93524-9_2.

Kasujja, K. M. (2018). Technology and Financial Desintermediation With a Special Reference To Blockchain and Islamic Finance. (master's thesis). Hamad Bin Khalifa University, College of Islamic Studies, Ar-Rayyan, Qatar.

Lambert, S. (2019). How Smart Contracts are Altering the Banking Industry Operations? Retrieved from https://yourstory.com/mystory/howsmart-contracts-are-altering-thebanking-indus.

Lee, J., Seo, A., Kim, Y., \& Jeong, J. (2018). Blockchain-Based One-Off Address System to Guarantee Transparency and Privacy for a 
Sustainable Donation Environment. Sustainability https://doi.org/10.3390/su10124422.

Nguyen, D. C., Ding, M., Pathirana, P. N., \& Seneviratne, A. (2020). Blockchain and AI-based Solutions to Combat Coronavirus (COVID19)-like Epidemics: A Survey. DOI: 10.36227/techrxiv.12121962.

Nor, R. M., Rahman, M. H., Rahman, T., \& Abdullah, A. (2017). BLOCKCHAIN SADAQA MECHANISM FOR DISASTER AID CROWD FUNDING. 6th International Conference on Computing and Informatics, (pp. 400-405). Kuala Lumpur. http://icoci.cms.net.my/PROCEEDI NGS/2017/Pdf_Versi...

Peredaryenko, M. (2019). FinTech, Blockchain, and Islamic Finance Building the Future in the New Islamic Digital Economy. Dans D. Guarda, R. Hussin, \& M. D. Babb, 4IR AI Blockchain Fintech IoT Reinventing a Nation. Kuala Lumpur, Malaysia.

Salleh, W. N., Abdul Rasid, S. Z., \& Basiruddin, R. (2019). Towards Transforming Zakat Collection and Distribution Roles using Digital Wallet in Support of Social Justice and Social Financing. Open International Journal of Informatics , 7 (2), 95-103. DOI: 10.1108/JIMA03-2017-.

Vrba, T. (2018). Decentralized Governance, Reputation and Mechanism Design for a Global Social Impact Funding Platform on a Public Blockchain. https://riskinnovation.asu.edu/wpcontent/uploads/2018/05/Vrba_RIL_ Blockchain_FinalProject_Part1.pdf.
Dhiaeddine Rejeb Sosyal Bilimler Enstitüsü Sakarya University dhiaeddine.rejeb@gmail.com ORCID iD : 0000-0002-0374-7228 